Check for updates

Cite this: RSC Adv., 2017, 7, 41512

Received 4th July 2017

Accepted 19th August 2017

DOI: $10.1039 / c 7 r a 07387 a$

rsc.li/rsc-advances

\section{Construction and evaluation of chemical structure model of Huolinhe lignite using molecular modeling †}

\author{
Fang Xu, ${ }^{\text {ab }}$ Shuo Pan, ${ }^{\mathrm{b}}$ Chunguang Liu, ${ }^{\mathrm{c}}$ Deng Zhao, ${ }^{a}$ Hui Liu, (D) *a Qing Wang ${ }^{* \mathrm{~b}}$ \\ and Ying Liu
}

Molecular model construction plays an important role in gaining insight into the thermal conversion process and reaction mechanism of lignite. Based on element analysis, solid-state ${ }^{13} \mathrm{C}$ nuclear magnetic resonance $\left({ }^{13} \mathrm{C}\right.$ NMR), X-ray photoelectron spectroscopy (XPS), and Fourier transform infrared (FTIR), a Huolinhe (HLH) lignite two dimensional (2D) molecular model was initially constructed. Concentrations of main covalent bonds were employed to adjust and examine the molecular model. The advantage of this approach is not only that it can solve the problem of selecting a representative isomer in constructing the model but also that it considers the essence of chemical reaction. The three dimensional (3D) minimum energy configuration was obtained by molecular mechanics (MM) and molecular dynamics (MD) calculation in Materials Studio package (Accelrys). Finally, the sequence of bond-cleavage from DTG analysis and molecular simulations were used to verify the rationality of proposed model. In general, this work has opened pathways in studying the lignite thermal reaction process at the molecular scale.

\section{Introduction}

Lignite storage in China reaches 130 billion tons, accounting for approximately $13 \%$ of global coal storage. ${ }^{1,2}$ With the highranking coal being gradually exhausted, the utilization of lignite has great potential in energy conversion processes. ${ }^{3}$ Because of its low mining cost, large amounts of volatiles as well as high chemical reactivity, lignite is being applied to a wide range of applications in the energy sector, such as pyrolysis, combustion, gasification, and liquefaction. ${ }^{4}$ However, because these coal utilization processes involve a myriad of coupled reaction pathways, it is difficult to explore these reaction mechanism just by experimental methods. ${ }^{5}$ Molecular simulation, recognized as 'the third way to explore real matter' provides a new approach to research these reaction processes. ${ }^{6}$ It should be pointed out that a rational lignite molecular model is supposed to be the key role in studying lignite conversion processes by molecular simulation. ${ }^{7}$

The first model of coal was proposed by Fuchs in $1942 .{ }^{8}$ Over the past 75 years, large number $(>134)$ of coal molecular models

${ }^{a}$ School of Energy Science and Engineering, Harbin Institute of Technology, Harbin, 150001, P. R. China.E-mail: liuhui@hit.edu.cn

${ }^{b}$ School of Energy and Power Engineering, Northeast Electric Power University, Jilin, 132012, P. R. China. E-mail: rlx888@126.com

${ }^{c}$ College of Chemical Engineering, Northeast Electric Power University, Jilin, 132012, P. R. China

$\dagger$ Electronic supplementary information (ESI) available: The detailed structural information of Huolinhe lignite model (PDF). See DOI: 10.1039/c7ra07387a have progressively appeared in the literature. ${ }^{9-12}$ However, the studies of lignite molecular models lag far behind. The first model of lignite was generated by Wender in $1976 .^{10}$ The proposed structure model only included 92 atoms with an average structural unit $\left(\mathrm{C}_{42} \mathrm{H}_{40} \mathrm{O}_{10}\right)$. Even so, Wender's model is the scientific foundation of lignite molecular model, which captures amount of important features of lignite structure. After that, Philip et al. ${ }^{11}$ published a model of lignite $\left(\mathrm{C}_{115} \mathrm{H}_{125} \mathrm{O}_{17} \mathrm{NS}\right)$ based on liquefaction products of lignite. It is worthwhile mentioning that a variety of further significant structural features (heteroatoms $\mathrm{N}$ and $\mathrm{S}$, esterified aliphatic side chain, and H-bonding) exist in lignite molecular model for the first time. Wolfrum et al. ${ }^{12}$ reported a brown coal molecular model $\left(\mathrm{C}_{227} \mathrm{H}_{183} \mathrm{O}_{35} \mathrm{~N}_{4} \mathrm{~S}_{3} \mathrm{CaFeAl}\right)$ by detailed analyzing its chemical structure features. It contains more structural heterogeneity and metal cations.

The development of numerical simulations and computer technologies are aiding demystification of the 3D models of coal. ${ }^{13}$ 3D structural model cannot only characterize the detailed structural information but also shine a light on thermal reaction process. ${ }^{14}$ A brown coal 3D structure unit $\left(\mathrm{C}_{21} \mathrm{H}_{20} \mathrm{O}_{7}\right)$ was created by Kumagai et al., ${ }^{15}$ who first obtained lignite model by taking advantage of computational chemistry to create a $3 \mathrm{D}$ periodic cell with one tetramer plus one pentamer. It is worth to note that the validity of the model is extremely significant. Considering that carbon content (C\%) and aromaticity $\left(f_{\mathrm{a}}\right)$ have always been utilized as the key parameters to characterize chemical structures of coal, researchers widely used ${ }^{13} \mathrm{C}$ NMR spectra to check and adjust 
the model. ${ }^{16,17}$ However, owing to the presence of amounts of isomers, structure model obtained by ${ }^{13} \mathrm{C}$ NMR spectra verification is only one conceptual image among a large number of graphical models. ${ }^{18}$ Furthermore, it is difficult to make use of conceptual images to correlate structures with reactivity.

It is generally agreed that the essence of chemical reaction is the breakage and rearrangement of chemical bonds. Guo et al. ${ }^{19}$ described that the complicated behavior of lignin pyrolysis could be simplified by only considering the changes in main covalent bonds. This idea was also practiced by Liu et al., ${ }^{20}$ they analyzed the peak temperature of DTG sub-curves which greatly matches with the cleavage of major covalent bonds during pyrolysis. Consequently, concentrations of main covalent bonds are thought to be more suitable to examine and adjust the model. Nevertheless, very little information is available for adjustment of coal molecular model by concentrations of main covalent bonds. ${ }^{21}$

For the purpose of filling the above knowledge gap, the initial 2D molecular model for HLH lignite was constructed according to chemical structure characteristics of coal. The main covalent bond concentrations of coal can be obtained by the information of ${ }^{13} \mathrm{C}$ NMR and ultimate analysis, while the bond concentrations of model can be determined using the number of bonds dividing the molecular weight of the model. The final 2D model can be generated by adjusting the covalent bond concentrations of the model to get close to experimental values. In the end, the correctness of the model is verified by comparing the results of experiments and simulations during the thermal reaction process. Compared to the real coal structure, the model is only an 'average structural unit' ${ }^{22}$ of coal, but it can give a reasonable representation of HLH lignite in terms of energy conversion process.

Table 1 Proximate and ultimate analyses of $\mathrm{HLH}$ lignite and elemental portion of the model (wt\%)

\begin{tabular}{|c|c|c|c|c|c|c|c|c|c|}
\hline \multirow[b]{2}{*}{ Sample } & \multicolumn{4}{|c|}{ Proximate analysis } & \multicolumn{5}{|c|}{ Ultimate analysis } \\
\hline & $\mathbf{M}_{\mathrm{ad}}$ & $\mathrm{A}_{\mathrm{ad}}$ & $\mathrm{FC}_{\mathrm{ad}}$ & $\mathrm{V}_{\text {daf }}$ & $\mathrm{C}_{\mathrm{daf}}$ & $\mathrm{H}_{\mathrm{daf}}$ & $\mathrm{O}_{\mathrm{daf}}^{\mathrm{a}}$ & $\mathrm{N}_{\mathrm{daf}}$ & $\mathrm{S}_{\mathrm{daf}}$ \\
\hline HLH lignite & 7.30 & 7.78 & 45.13 & 47.23 & 75.40 & 6.14 & 16.00 & 1.46 & 1.00 \\
\hline Model & & & & & 75.52 & 6.15 & 16.02 & 1.31 & 1.00 \\
\hline
\end{tabular}

\section{Experimental and computational details}

\subsection{Sample}

HLH lignite samples used in this work were obtained from Inner Mongolia. They were crushed and grounded to $109-180 \mu \mathrm{m}$, and then were dried under vacuum at $40{ }^{\circ} \mathrm{C}$ for $24 \mathrm{~h}$ before used. The proximate and ultimate analyses results are shown in Table 1.

\subsection{Structural characteristic analysis}

2.2.1 ${ }^{13} \mathrm{C}$ NMR spectra analysis. ${ }^{13} \mathrm{C}$ NMR spectroscopic measurement for $\mathrm{HLH}$ lignite was conducted at $100.64 \mathrm{MHz}$ by using a Bruker Avance III $400 \mathrm{MHz}$ spectrometer, which was equipped with a $4 \mathrm{~mm}$ cross polarization magic angle spinning double-resonance probe head. The contact time, recycle delay time, and accumulative number of collected data were set to $2 \mathrm{~ms}, 6 \mathrm{~s}$, and 9000 respectively. MestReNova software was used to analyze ${ }^{13} \mathrm{C}$ NMR spectra of coal, amounts of carbon skeleton structural parameters were got by integration of the different chemical shifts. ${ }^{23}$ The results are shown in Table 2 .

2.2.2 XPS spectra analysis. To obtain the surface composition of HLH lignite, $\mathrm{C} 1 \mathrm{~s}, \mathrm{~N}$ 1s and $\mathrm{S} 2 \mathrm{p}$ spectrum were determined using a Thermo VG Scientific ESCALAB 250Xi spectrometer and curve-resolved with Casa XPS processing software. ${ }^{24}$ In addition, all corrections for binding energies were carried out in reference the principal C 1 s peak at $284.8 \mathrm{eV}^{25}$ The data about carbon, oxygen, nitrogen and sulfur forms are listed in Table 3.

2.2.3 FTIR analysis. The characteristics of functional groups for HLH lignite were measured by Nicolet-6700 FTIR spectrometer. The spectra was recorded in the range of 4000 to $400 \mathrm{~cm}^{-1}$ with a resolution of $4 \mathrm{~cm}^{-1}$. The sample $(1 \mathrm{mg})$ with $\mathrm{KBr}(150 \mathrm{mg})$ were powered for $2 \mathrm{~min}$ and pressed into a pellet, after that dried in a vacuum oven under $60{ }^{\circ} \mathrm{C}$ for $12 \mathrm{~h}$. The infrared spectra of HLH lignite are shown in Fig. 1.

2.2.4 DTG analysis. The pyrolysis behavior of HLH lignite was studied by a thermogravimetric analyzer (TGA) from MetterToledo. The experiments were performed from $30{ }^{\circ} \mathrm{C}$ to $110{ }^{\circ} \mathrm{C}$ at $10{ }^{\circ} \mathrm{C} \mathrm{min}{ }^{-1}$ and maintain $30 \mathrm{~min}$ at $110{ }^{\circ} \mathrm{C}$, then from $110{ }^{\circ} \mathrm{C}$ to $900{ }^{\circ} \mathrm{C}$ with the same heating rate. High purity helium

Table 2 Assignments for peaks in ${ }^{13} \mathrm{C}$ NMR spectra and relative content

\begin{tabular}{|c|c|c|c|c|}
\hline Carbon distribution & Chemical shift (ppm) & Structural fragments & Symbols & Relative content (\%) \\
\hline \multirow[t]{5}{*}{ Aliphatic carbon $34.32 \%$} & $14-16$ & Aliphatic $\mathrm{CH}_{3}$ & $f_{\mathrm{al}}^{\mathrm{M}}$ & 1.24 \\
\hline & $16-22$ & Aromatic $\mathrm{CH}_{3}$ & $f_{\mathrm{al}}^{\mathrm{A}}$ & 4.89 \\
\hline & $22-36$ & Methylene & $f_{\mathrm{al}}^{\mathrm{H}}$ & 17.60 \\
\hline & $36-50$ & Methine quaternary & $f_{\mathrm{al}}^{\mathrm{D}}$ & 8.74 \\
\hline & $50-90$ & Oxy-aliphatic carbon & $f_{\mathrm{al}}^{\mathrm{O}}$ & 1.85 \\
\hline \multirow[t]{4}{*}{ Aromatic carbon $61.25 \%$} & $100-129$ & Aromatic protonated & $f_{\mathrm{ar}}^{\mathrm{H}}$ & 27.83 \\
\hline & $129-137$ & Aromatic bridgehead & $f_{\text {ar }}^{\mathrm{B}}$ & 10.64 \\
\hline & $137-148$ & Aromatic branched & $f_{\mathrm{ar}}^{\mathrm{E}}$ & 12.61 \\
\hline & $148-165$ & Oxy-aromatic carbon & $f_{\text {ar }}^{\mathrm{O}}$ & 10.17 \\
\hline \multirow[t]{2}{*}{ Carbonyl carbon $4.43 \%$} & $165-180$ & Carboxyl carbon & $f_{\mathrm{a}}^{\mathrm{C}}$ & 2.44 \\
\hline & $180-220$ & Carbonyl carbon & $f_{\mathrm{a}}^{\mathrm{o}}$ & 1.99 \\
\hline
\end{tabular}


Table 3 Distributions of carbon, oxygen, nitrogen, and sulfur forms in $\mathrm{HLH}$ lignite from XPS analysis

\begin{tabular}{lllc}
\hline $\begin{array}{l}\text { Elemental } \\
\text { peak }\end{array}$ & Functionality & $\begin{array}{l}\text { Binding energy } \\
(\mathrm{eV})\end{array}$ & $\begin{array}{l}\text { Molar content } \\
(\%)\end{array}$ \\
\hline C 1s & C-C & 284.8 & 82.00 \\
& C=O & 287.5 & 1.67 \\
& C-O & 286.3 & 13.86 \\
N 1s & O-C=O & 289.0 & 2.48 \\
& Pyridinic & 398.7 & 18.07 \\
& Pyrrolic & 400.1 & 54.58 \\
& Quaternary nitrogen & 401.3 & 15.25 \\
S 2p & Nitrogen oxide & 402.8 & 12.1 \\
& Aliphatic sulfur & $163.5 \& 164.7$ & 29.15 \\
& Aromatic sulfur & $164.2 \& 165.4$ & 35.6 \\
& Sulfoxide & $165.4 \& 166.6$ & 4.53 \\
& Sulfone & $169.4 \& 170.6$ & 30.72
\end{tabular}

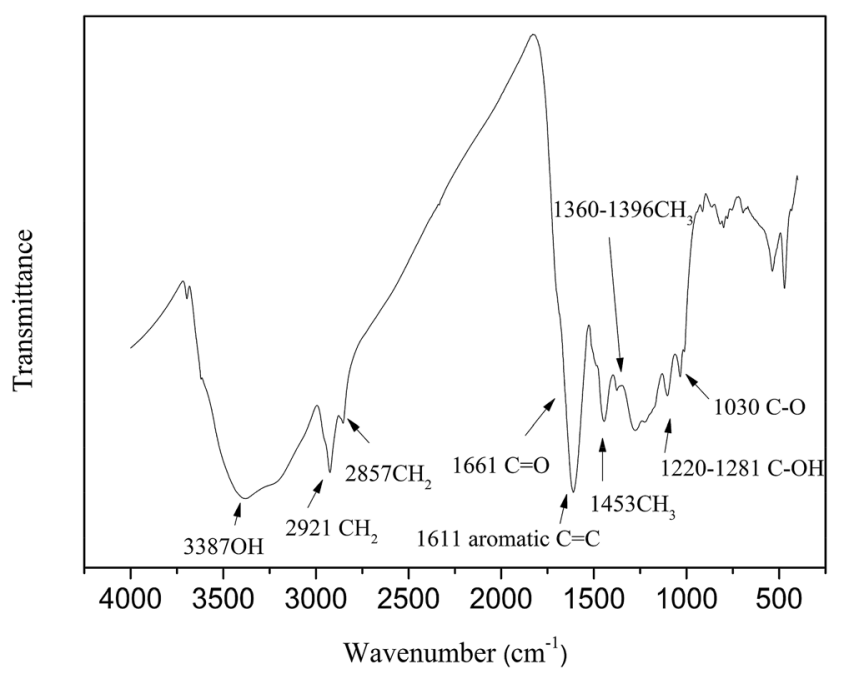

Fig. 1 FTIR spectra of HLH lignite.

$(99.999 \%)$ was utilized at $50 \mathrm{~mL} \mathrm{~min}^{-1}$ to make sure an inert atmosphere. ${ }^{26}$ The differential thermogravimetric (DTG) curve was fitted by 6 sub-curves with a high correlation coefficient $\left(R^{2}\right.$ $=0.9919)$. Liu et al. ${ }^{20}$ suggested a series of sub-curves can represent a group of covalent bonds. Therefore, the sequence of bond-cleavage can be obtained by DTG analysis.

\subsection{Computational methods and model construction}

2.3.1 Computational methods. The optimal geometry structure was obtained by MM and MD calculations in Materials Studio package (Accelrys). MM calculations were performed using Forcite module. Calculation details: task, geometry optimization; minimization algorithm, smart minimizer; quality, fine; $\max$ iterations, 5000; energy differences, $0.0001 \mathrm{kcal} \mathrm{mol}^{-1}$; RMS force, $0.005 \mathrm{kcal} \mathrm{mol}^{-1} \mathrm{~A}^{-1}$; charge equilibration method, QEq; the calculated electrostatic energy and van der Waals energy was based on atoms; force field, Dreiding. ${ }^{27}$ And then, MD calculations were carried out by the anneal dynamics in the same module. Calculation details: initial temperature, $300 \mathrm{~K}$; mid-cycle temperature, $600 \mathrm{~K}$; heating ramps per cycle, 5; dynamics steps per ramp, 100; annealing cycles, 10; ensemble, NVT; thermostat, Nosé. Simulation time, 200 ps. For the purpose of getting a low energy state, geometry optimization with above parameters was carried out on the output configuration after each cycle.

The structure was further refined by using DFT method at the B3LYP/3-21g basis set. Natural bond orbital (NBO) analysis ${ }^{28}$ was performed to assign the atomic charges and Wiberg bond indices (WBI) at the same levels with the Gaussian 09 package. ${ }^{29}$ NBO analysis is a good tool for getting bond length and bond order, which can analyze the bond-cleavage behavior of the model.

2.3.2 Model construction. The construction procedure of HLH lignite model is shown in Fig. 2. The initial 2D model can be constructed based on elemental analysis, spectra of ${ }^{13} \mathrm{C}$ NMR, XPS, and FTIR. ${ }^{30,31}$ Concentrations of main covalent bonds have been used to adjust the molecular model. And then, optimal geometry 3D structure was obtained by MM and MD calculations in Materials Studio package (Accelrys). Finally, the model was evaluated by comparing the bond-cleavage sequence from DTG analysis and molecular simulations.

\subsection{Calculation of covalent bond concentrations of model and HLH lignite}

It is generally accepted that coal mainly involves 11 types of covalent bonds. Since the contents of S and $\mathrm{N}$ in coal are usually very low, only 9 types of bonds have been considered in the study including $\mathrm{C}_{\mathrm{ar}}-\mathrm{C}_{\mathrm{ar}}, \mathrm{C}_{\mathrm{ar}}-\mathrm{C}_{\mathrm{al}}, \mathrm{C}_{\mathrm{al}}-\mathrm{C}_{\mathrm{al}}, \mathrm{C}_{\mathrm{ar}}-\mathrm{H}, \mathrm{C}_{\mathrm{al}}-\mathrm{H}, \mathrm{C}_{\mathrm{ar}}-\mathrm{O}$, $\mathrm{C}_{\mathrm{al}}-\mathrm{O}, \mathrm{C}_{\mathrm{al}}=\mathrm{O}$, and $\mathrm{O}-\mathrm{H}$. These bond concentrations of model can be determined by eqn (1). ${ }^{21}$

$$
\operatorname{con}_{\mathrm{i}-\mathrm{j}}=\frac{n_{\mathrm{i}-\mathrm{j}}}{12 n_{\mathrm{C}}+n_{\mathrm{H}}+16 n_{\mathrm{O}}+32 n_{\mathrm{S}}+14 n_{\mathrm{N}}}
$$

here $\operatorname{con}_{\mathrm{i}-\mathrm{j}}$ denotes the concentration of bond $\mathrm{i}-\mathrm{j} ; n_{\mathrm{i}-\mathrm{j}}$ is the amount of bond $\mathrm{i}-\mathrm{j}$ in a molecule; i represents $\mathrm{C}_{\mathrm{ar}}, \mathrm{C}_{\mathrm{al}}$, and $\mathrm{O}$, while $\mathrm{j}$ represents $\mathrm{C}_{\mathrm{ar}}, \mathrm{C}_{\mathrm{al}}$ or $\mathrm{H}$; the denominator is the molecular weight of the model.

The concentrations of 9 types covalent bonds in coal can be determined by eqn (2)-(10), ${ }^{21}$ which can calculate the quantity of the single bond, double bonds, and quasi-double bonds. This method was modified from the work of Gyul'maliev et al. ${ }^{32}$ who reported the quantity of the bonds could be determined by half of the unpaired electrons in the system only considering the single bond.

$$
\begin{gathered}
\operatorname{con}_{\mathrm{C}_{\mathrm{ar}}-\mathrm{C}_{\mathrm{ar}}}=\frac{1}{2}\left[\frac{\mathrm{C} \%}{12}\left(3 f_{\mathrm{ar}}-f_{\mathrm{ar}}^{\mathrm{H}}-f_{\mathrm{ar}}^{\mathrm{C}}-f_{\mathrm{ar}}^{\mathrm{O}}\right)\right] \\
\operatorname{con}_{\mathrm{Car}_{\mathrm{ar}}-\mathrm{C}_{\mathrm{al}}}=\frac{\mathrm{C} \%}{12} f_{\mathrm{ar}}^{\mathrm{C}} \\
\operatorname{con}_{\mathrm{C}_{\mathrm{al}}-\mathrm{C}_{\mathrm{al}}}=\frac{1}{2}\left[\frac{\mathrm{C} \%}{12}\left(4 f_{\mathrm{al}}+2 f_{\mathrm{a}}^{\mathrm{C}}+2 f_{\mathrm{a}}^{\mathrm{O}}-f_{\mathrm{ar}}^{\mathrm{C}}-f_{\mathrm{al}}^{\mathrm{O}}\right)-n_{\mathrm{Cal}-\mathrm{H}}\right] \\
=-\frac{\mathrm{H}^{\mathrm{O}} \%}{2}+\frac{\mathrm{O} \%}{16} \\
+\frac{1}{2}\left[\frac{\mathrm{C} \%}{12}\left(4 f_{\mathrm{al}}+f_{\mathrm{ar}}^{\mathrm{H}}-f_{\mathrm{ar}}^{\mathrm{C}}-f_{\mathrm{ar}}^{\mathrm{O}}-2 f_{\mathrm{al}}^{\mathrm{O}}-f_{\mathrm{a}}^{\mathrm{C}}\right)\right]
\end{gathered}
$$




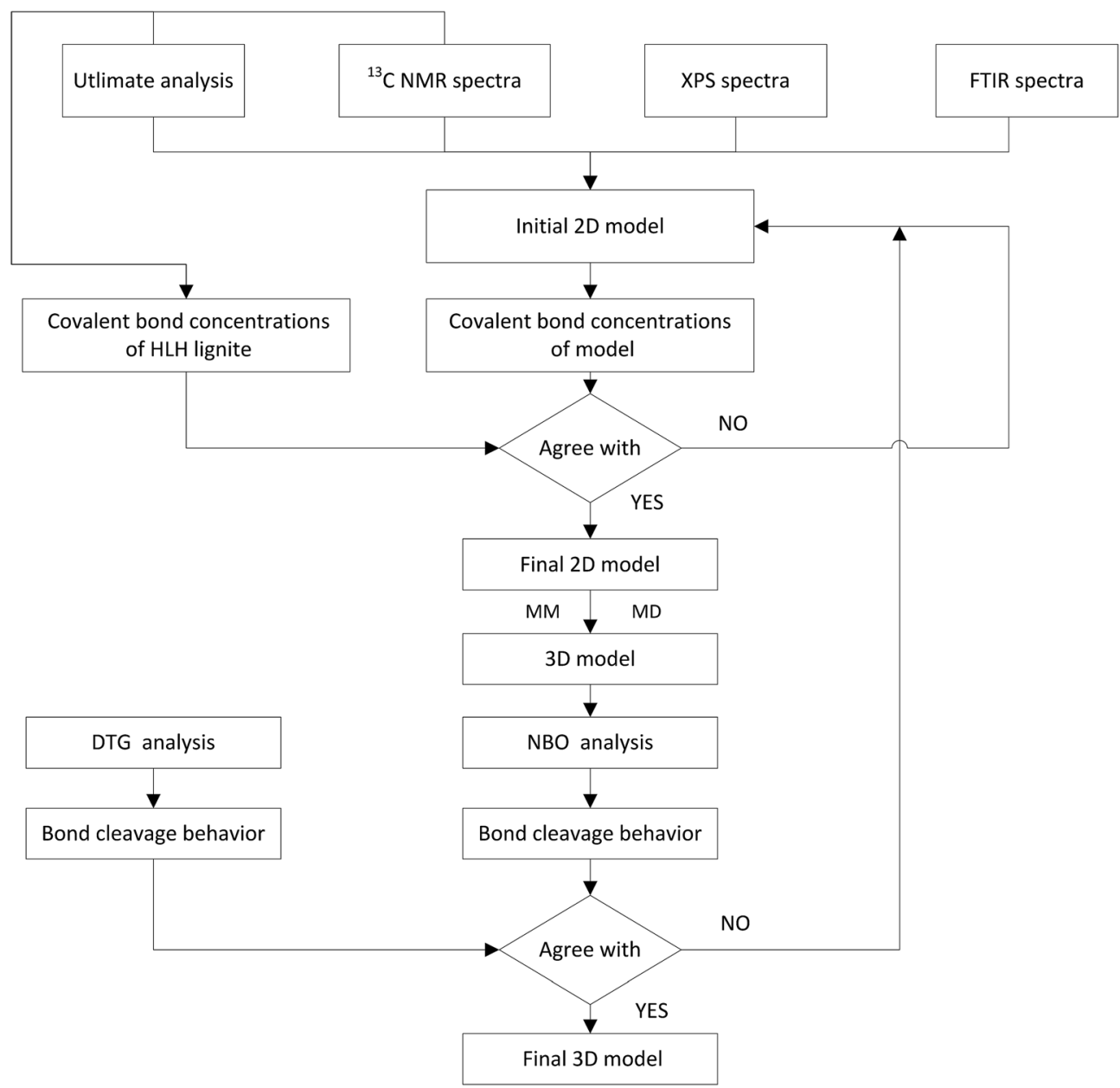

Fig. 2 Schematic diagram for the construction of HLH lignite structural model.

$$
\begin{gathered}
\operatorname{con}_{\mathrm{Car}_{\mathrm{ar}}-\mathrm{H}}=\frac{\mathrm{C} \%}{12} f_{\mathrm{ar}}^{\mathrm{H}} \\
\operatorname{con}_{\mathrm{Cal}_{\mathrm{a}} \mathrm{H}}=\mathrm{H} \%-\operatorname{con}_{\mathrm{O}-\mathrm{H}}-\operatorname{con}_{\mathrm{Car}_{\mathrm{ar}}-\mathrm{H}} \\
\mathrm{H}^{\mathrm{O}} \%-2 \frac{\mathrm{O} \%}{16}+\frac{\mathrm{C} \%}{12}\left(f_{\mathrm{ar}}^{\mathrm{O}}+f_{\mathrm{al}}^{\mathrm{O}}+2 f_{\mathrm{a}}^{\mathrm{O}}+3 f_{\mathrm{a}}^{\mathrm{C}}-f_{\mathrm{ar}}^{\mathrm{H}}\right) \\
\operatorname{con}_{\mathrm{Car}-\mathrm{O}}=\frac{\mathrm{C} \%}{12} f_{\mathrm{ar}}^{\mathrm{O}} \\
\operatorname{con}_{\mathrm{Cal}_{\mathrm{a}} \mathrm{O}}=\frac{\mathrm{C} \%}{12}\left(f_{\mathrm{al}}^{\mathrm{O}}+f_{\mathrm{a}}^{\mathrm{C}}\right) \\
\operatorname{con}_{\mathrm{Cal}_{\mathrm{al}}=\mathrm{O}}=\frac{\mathrm{C} \%}{12}\left(f_{\mathrm{a}}^{\mathrm{C}}+f_{\mathrm{a}}^{\mathrm{O}}\right) \\
\operatorname{con}_{\mathrm{O}-\mathrm{H}}=\frac{2 \mathrm{O} \%}{16}-\frac{\mathrm{C} \%}{12}\left(f_{\mathrm{ar}}^{\mathrm{O}}+f_{\mathrm{al}}^{\mathrm{O}}+3 f_{\mathrm{a}}^{\mathrm{C}}+2 f_{\mathrm{a}}^{\mathrm{O}}\right)
\end{gathered}
$$

\section{Results and discussion}

\subsection{HLH lignite molecular model construction}

A formula of $\mathrm{C}_{200} \mathrm{H}_{195} \mathrm{~N}_{3} \mathrm{~S}_{1} \mathrm{O}_{32}$ can be determined for $\mathrm{HLH}$

here $f_{\mathrm{ar}}$ represents aromaticity; $f_{\mathrm{ar}}^{\mathrm{H}}$ represents the fraction of protonated aromatic carbons; $f_{\mathrm{ar}}^{\mathrm{C}}$ is the ratio of alkylated aromatic carbons; $f_{\text {ar }}^{\mathrm{O}}$ is the ratio of aromatic carbons bonded to oxygen; $f_{\mathrm{al}}$ is the ratio of aliphatic carbons; $f_{\mathrm{a}}^{\mathrm{C}}$ denotes the fraction of carboxyl carbon; $f_{\mathrm{a}}^{\mathrm{O}}$ denotes the ratio of carbonyl carbon; $f_{\mathrm{al}}^{\mathrm{O}}$ is the ratio of aliphatic carbons bonded to oxygen. lignite from elemental analysis, whose magnitude is consistent with Yuzhou lignite (molecular formula of $\mathrm{C}_{240} \mathrm{H}_{211} \mathrm{~N}_{3} \mathrm{SO}_{76}$ ). ${ }^{33}$ According to the aforementioned results of XPS analysis and the number of $\mathrm{S}$ and $\mathrm{N}$ in the formula, thiophene, pyridine, and two pyrrole were selected as representative heterocycles in the model. After that, we began to determine the type of aromatic structures. Aromatic carbon, accounting for $61.25 \%$, constitute the skeletal structure of molecular model. The number and type of aromatic unit structures can be determined by $X_{\mathrm{b}}$ (the molar fraction of aromatic bridgehead carbon), the number of aromatic carbon, and aromatic bridgehead carbon. $X_{\mathrm{b}}$ determined by eqn (11) is a significant parameter that can be employed to analyze the aromatic cluster size. ${ }^{34}$ The $X_{\mathrm{b}}$ calculated for HLHM is 0.17 , which gets closer to naphthalene $\left(X_{\mathrm{b}}=\right.$ 0.2 ), suggesting that the amount of aromatic rings in aromatic clusters is rarely greater than two. ${ }^{35}$ Hence, we choose benzene and naphthalene as the main aromatic structural units. The type and quantity of aromatic structures in the model are listed in Table 4. 
Table 4 The type and quantity of aromatic unit structures

\begin{tabular}{llll}
\hline Type & Quantity & Type & Quantity \\
\hline
\end{tabular}

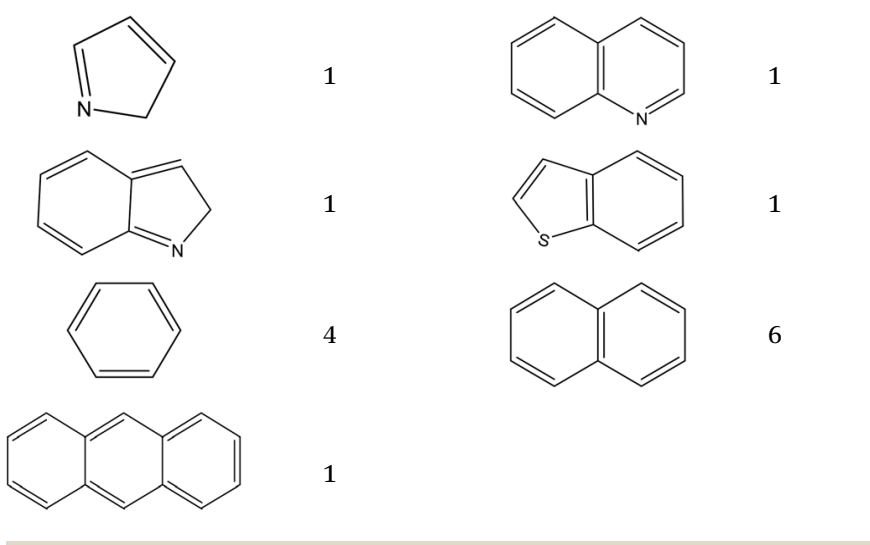

$$
X_{\mathrm{b}}=f_{\mathrm{ar}}^{\mathrm{B}} / f_{\mathrm{ar}}
$$

For additions of aliphatic side chains, there is no way knowing how these aliphatic carbons are linked to each other or other structural units. ${ }^{36}$ We can only know aliphatic carbon structural parameters: the average methylene chain length $C_{\mathrm{n}}=$ 1.4 , branched degree of aliphatic chain $\mathrm{BI}=25.47 \% . C_{\mathrm{n}}$ and $\mathrm{BI}$ were determined by eqn (12) and (13). ${ }^{37}$ On the basis of these results, it can be concluded that aliphatic structural units mainly exist in the form of short chain and branch structure.

$$
\begin{gathered}
C_{\mathrm{n}}=f_{\mathrm{al}}^{\mathrm{H}} / f_{\mathrm{ar}}^{\mathrm{H}} \\
\mathrm{BI}=f_{\mathrm{al}}^{\mathrm{D}} / f_{\mathrm{a} a}
\end{gathered}
$$

As shown in Fig. 1, the oxygen functional group in HLH lignite exist in different forms, such as carboxyl, carbonyl, hydroxyl, and ether. Oxygen forms can be also determined by analyzing oxygen's influence on the XPS carbon (1s) signal of adjacent carbon atoms. ${ }^{38}$ Table 3 shows the proportion of carbon bound to oxygen by two oxygen bonds $(\mathrm{C}=\mathrm{O})$ and carbon bound to oxygen by three bonds $(\mathrm{O}=\mathrm{C}-\mathrm{O})$ are much smaller, which agrees with the results of FTIR and ${ }^{13} \mathrm{C}$ NMR spectra analysis. The carbon bound to one oxygen by a single bond (e.g., $\mathrm{C}-\mathrm{O}, \mathrm{C}-\mathrm{OH}$, etc.) is the main existence of oxygen. However, little information regarding the distribution of ether (C-O) and hydroxyl (C-OH) can be obtained by XPS and ${ }^{13} \mathrm{C}$ NMR spectra analysis. The final forms of oxygen in molecular structure can be achieved through model adjustment. At last, 2D molecular model was initially constructed according to chemical structural characteristics getting by experimental methods.

\subsection{Adjustment of HLH lignite molecular model}

Simulated ${ }^{13} \mathrm{C}$ NMR spectra has always been taken so as to 'adjust' model structures to get close to experimental data. Although the carbon skeleton structure of model can be identical with the experimental value, it cannot avoid the problem of choosing representative isomer. Isomers with the same molecular formula have a great difference in reactivity, more often than not the reason might be found in the form of chemical bond connection. Meanwhile, the model got by this method is only a conceptual image, which cannot reflect the nature of the chemical reaction. The reactivity of models was often obviously lower than the actual values. ${ }^{\mathbf{1 6 , 3 9}}$ Concentrations of main covalent bonds instead of simulated ${ }^{13} \mathrm{C}$ NMR spectra can be employed to check and adjust molecular model. Nine bonds concentrations of HLH lignite can be got according to ${ }^{13} \mathrm{C}$ NMR data and the ultimate analysis data. Eqn (2)-(10) contain nearly

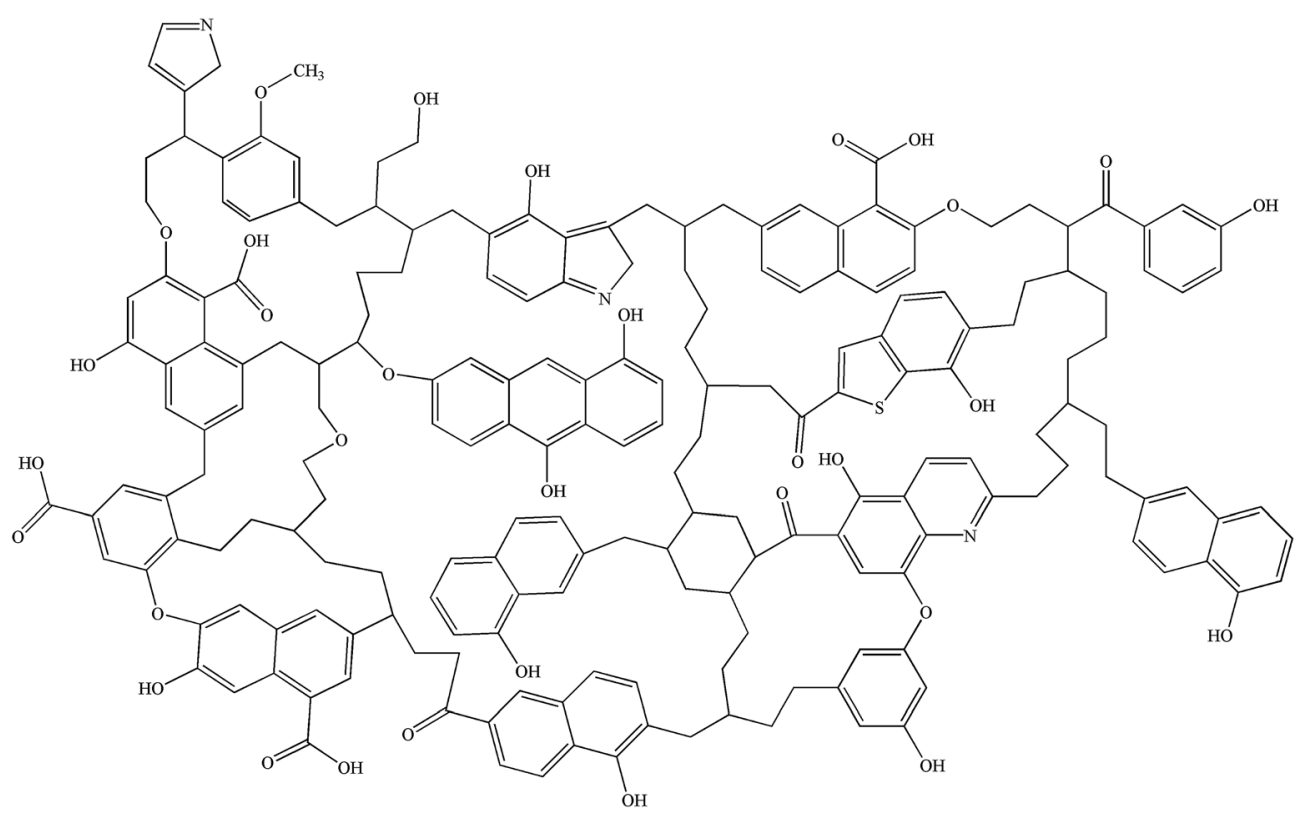

Fig. 3 The final 2D molecular model of HLH lignite. 
Table 5 Main covalent bond concentrations of HLH lignite and model $\left(\mathrm{mmol} \mathrm{g}^{-1}\right)$

\begin{tabular}{|c|c|c|c|c|c|c|c|c|c|}
\hline Sample & $\operatorname{con}_{\mathrm{C}_{\mathrm{ar}}-\mathrm{C}_{\mathrm{ar}}}$ & $\operatorname{con}_{\mathrm{C}_{\mathrm{ar}}-\mathrm{C}_{\mathrm{al}}}$ & $\operatorname{con}_{\mathrm{C}_{\mathrm{al}}-\mathrm{C}_{\mathrm{al}}}$ & $\operatorname{con}_{\mathrm{C}_{\mathrm{ar}}-\mathrm{H}}$ & $\operatorname{con}_{\mathrm{C}_{\mathrm{al}}-\mathrm{H}}$ & $\operatorname{con}_{\mathrm{C}_{\mathrm{ar}}-\mathrm{O}}$ & $\operatorname{con}_{\mathrm{C}_{\mathrm{al}}-\mathrm{O}}$ & $\operatorname{con}_{\mathrm{C}_{\mathrm{al}}}=\mathrm{O}$ & $\operatorname{con}_{\mathrm{O}-\mathrm{H}}$ \\
\hline HLH lignite & 41.83 & 7.92 & 22.09 & 17.94 & 38.56 & 6.39 & 2.70 & 2.78 & 5.35 \\
\hline Model & 41.97 & 7.51 & 20.02 & 18.76 & 36.91 & 6.26 & 2.19 & 2.50 & 5.32 \\
\hline
\end{tabular}
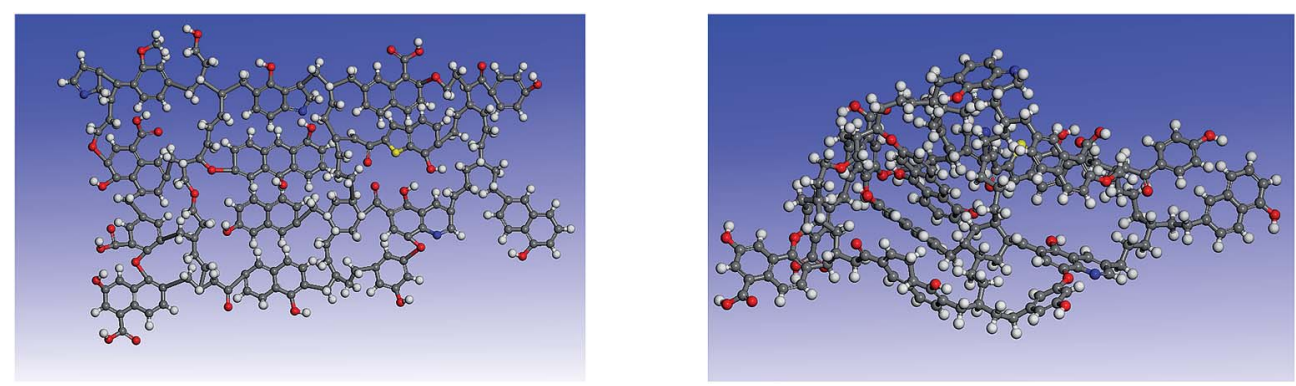

Fig. 4 The 3D structures of HLH lignite model before and after geometry optimization. (a) The initial 3D structural model of HLH lignite (b) the optimal geometry structure obtained by MM and MD calculation.

Table 6 Energy changes of $\mathrm{HLH}$ lignite model before and after geometry optimization ( $\mathrm{kcal} \mathrm{mol}^{-1}$ )

\begin{tabular}{|c|c|c|c|c|c|c|c|c|}
\hline Final structure & 96.24 & 146.18 & 119.45 & 4.00 & -7.26 & 403.72 & -52.64 & 709.67 \\
\hline
\end{tabular}

all carbon structural parameters structural features $\left(f_{\text {ar }}\right.$, $f_{\mathrm{ar}}^{\mathrm{H}}, f_{\mathrm{ar}}^{\mathrm{C}}, f_{\mathrm{ar}}^{\mathrm{O}}, f_{\mathrm{al}}, f_{\mathrm{a}}^{\mathrm{C}}, f_{\mathrm{a}}^{\mathrm{O}}$, and $\left.f_{\mathrm{al}}^{\mathrm{O}}\right)$ determined by ${ }^{13} \mathrm{C}$ NMR. It can be speculated that the method of covalent concentrations embodies the essence of simulated ${ }^{13} \mathrm{C}$ NMR spectra method. The preliminary 2D molecular model was modified by the comparison between the simulated concentrations of main covalent bonds and the experimental results. The final 2D molecular model is shown in Fig. 3. Table 5 lists 9 main covalent bond concentrations of HLH lignite and model. Geometry optimization 3D configuration of HLH lignite was produced by MM and MD calculations in Materials Studio package (Accelrys) and the structures before and after optimization are shown in Fig. 4(a and b). The detailed structural information of optimal geometry configuration is shown in Table S1 of the ESI. $\dagger$ The changes of energy are listed in Table 6 . It can be seen the total energy of optimized structure decreased sharply, only accounting for approximately $5 \%$ of initial structure. And more, optimized structure becomes much more compact with excellent spatial structure.

\subsection{Model evaluation}

The purpose of constructing lignite molecular model is mainly to research the thermal reaction process by molecular simulation. Therefore, the sequence of bond-cleavage reactions is more reasonable for evaluation of model.
3.3.1 Sub-curves of DTG analysis. TG analysis is a technique that used to study the relationship between the sample mass and reaction temperature in control process. ${ }^{40}$ The changes of mass during reaction are mainly caused by the breakage of bonds. Therefore, TG analysis can be employed to obtain the sequence of bond cleavage. Liu et al. ${ }^{20}$ demonstrated that DTG curve of coal pyrolysis could be fitted by a series of sub-curves which can represent a number of covalent bonds in coal. In this study DTG peaks were fitted by using 6 sub-curves

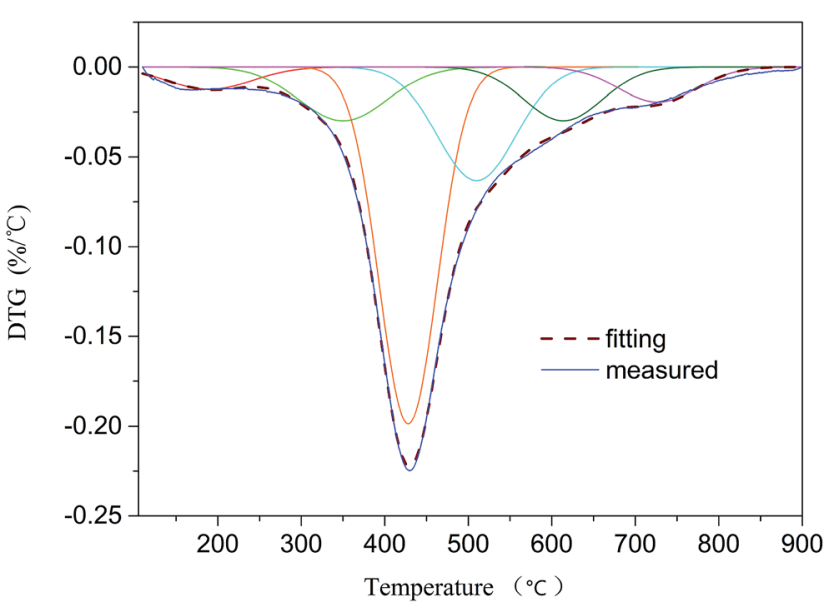

Fig. 5 DTG curve and fitting results. 
Table 7 Assignment of peaks from DTG profile

\begin{tabular}{lll}
\hline & & \\
Peak no. & Possible origin & $\begin{array}{l}\text { Peak temperature } \\
\left({ }^{\circ} \mathrm{C}\right)\end{array}$ \\
\hline 1 & Release of bonded & 190 \\
& water and decarboxylation & \\
2 & Cleavage of $\mathrm{C}_{\mathrm{al}}-\mathrm{O}, \mathrm{C}_{\mathrm{al}}-\mathrm{S}$, and $\mathrm{C}_{\mathrm{al}}-\mathrm{N}$ & 350 \\
3 & Cleavage of $\mathrm{C}_{\mathrm{al}}-\mathrm{C}_{\mathrm{al}}, \mathrm{C}_{\mathrm{al}}-\mathrm{H}$, and $\mathrm{C}_{\mathrm{ar}}-\mathrm{N}$ & 428 \\
4 & Cleavage of $\mathrm{C}_{\mathrm{ar}}-\mathrm{C}_{\mathrm{al}}, \mathrm{C}_{\mathrm{ar}}-\mathrm{O}$, and $\mathrm{C}_{\mathrm{ar}}-\mathrm{S}$ & 510 \\
5 & Carbonate decomposition & 614 \\
6 & Condensation of aromatic rings & 727 \\
\hline
\end{tabular}

$\left(R^{2}=0.9919\right.$; see Fig. 5). As shown in Table 7, 6 peaks were detected at $190,350,428,510,614$, and $727^{\circ} \mathrm{C}$. According to the studies proposed by He et al., ${ }^{3}$ Liu et al., ${ }^{20}$ and Li et al., ${ }^{26}$ peak 1 at temperature of $190{ }^{\circ} \mathrm{C}$ may be ascribed to the release of $\mathrm{H}_{2} \mathrm{O}$ and $\mathrm{CO}_{2}$. The assignment of peak 2 at $350{ }^{\circ} \mathrm{C}$ is likely to $\mathrm{C}_{\mathrm{al}}-\mathrm{O}$, $\mathrm{C}_{\mathrm{al}}-\mathrm{S}$, or $\mathrm{C}_{\mathrm{al}}-\mathrm{N}$. Peak 3 at $428{ }^{\circ} \mathrm{C}$ corresponds to $\mathrm{C}_{\mathrm{al}}-\mathrm{C}_{\mathrm{al}}, \mathrm{C}_{\mathrm{al}}-\mathrm{H}$, or $\mathrm{C}_{\mathrm{ar}}-\mathrm{N}$. Peak 4 detected at $510{ }^{\circ} \mathrm{C}$ can be attributed to $\mathrm{C}_{\mathrm{ar}}-\mathrm{C}_{\mathrm{al}}$, $\mathrm{C}_{\mathrm{ar}}-\mathrm{O}$, or $\mathrm{C}_{\mathrm{ar}}-\mathrm{S}$. Peak 5 at $614^{\circ} \mathrm{C}$ is related to decomposition of carbonates to generate $\mathrm{CO}_{2}$. Peak 6 at $727^{\circ} \mathrm{C}$ is thought to be the condensation of aromatic rings. It is concluded that the breakage of the weakest bonds ( such as $\mathrm{C}_{\mathrm{al}}-\mathrm{O}, \mathrm{C}_{\mathrm{al}}-\mathrm{S}$, and $\mathrm{C}_{\mathrm{al}}-\mathrm{N}$ ) occur in the initial stage. During the second stage, the cleavage of the weaker bonds (e.g., $\mathrm{C}_{\mathrm{al}}-\mathrm{C}_{\mathrm{al}}, \mathrm{C}_{\mathrm{al}}-\mathrm{H}$, and $\mathrm{C}_{\mathrm{ar}}-\mathrm{N}$ ) occur at mild temperature. In the end, $\mathrm{C}_{\mathrm{ar}}-\mathrm{C}_{\mathrm{al}}, \mathrm{C}_{\mathrm{ar}}-\mathrm{O}$, and $\mathrm{C}_{\mathrm{ar}}-\mathrm{S}$ with higher bond energy are difficult to crack. Since the main decomposition of volatiles occur in the temperature range of $300-600{ }^{\circ} \mathrm{C}$, the study of bond-cleavage only take peak 2,3 , and 4 into account. The major source for tar formation may be the cleavage of $\mathrm{C}_{\mathrm{al}}-\mathrm{C}_{\mathrm{al}}$ and $\mathrm{C}_{\mathrm{ar}}-\mathrm{C}_{\mathrm{al}}$ bonds which related to peak 3 and peak 4 , respectively. Therefore, optimum temperature for the yield of tar is around the temperature of peak 4 .

3.3.2 NBO analysis. The natural of chemical reaction is the breakage and recombination of chemical bonds during the reaction process. The bond strength is often related to bond length and bond order. Longer the bond, the smaller bond

Table 8 The average bond parameters of $\mathrm{HLH}$ lignite molecular model

\begin{tabular}{lll}
\hline Bond type & Bond length $(\AA)$ & Bond order \\
\hline C(heterocycle)-S(heterocycle) & 1.816 & 1.086 \\
C(heterocycle)-N(heterocycle) & 1.375 & 1.400 \\
C(carbonyl)=O(carbonyl) & 1.231 & 1.729 \\
C(carboxyl)=O(carboxyl) & 1.247 & 1.759 \\
C(carboxyl)-O(carboxyl) & 1.389 & 1.027 \\
C(aromatic)-O(phenol) & 1.391 & 1.031 \\
C(aromatic)-O(ether) & 1.432 & 0.942 \\
C(aliphatic)-O(ether,hydroxy) & 1.452 & 0.947 \\
C(aromatic)-C(aromatic) & 1.413 & 1.335 \\
C(aliphatic)-C(aliphatic) & 1.555 & 0.993 \\
C(aliphatic)-C(carbonyl) & 1.510 & 1.010 \\
C(aromatic)-C(carbonyl) & 1.490 & 1.044 \\
C(aliphatic)-C(aromatic) & 1.518 & 1.008
\end{tabular}

order and the easier the bond ruptures. $\mathrm{Ru}$ et al. ${ }^{\mathbf{4 1}}$ predicted reaction sites of Huadian kerogen according to bond length and bond order. NBO analysis is a helpful for gaining information on bond characters. ${ }^{42}$ The average bond parameters of HLH lignite molecular model are listed in Table 8.

It can be seen that the $\mathrm{C}-\mathrm{S}$ bond existing in thiophene has the longest bond length and the lower bond order, and can easily break at the beginning of the reaction. This is consistent with the study of Miura et al.,$^{43}$ who proposed that the release of $\mathrm{SO}_{2}$ during pyrolysis is approximately at $300{ }^{\circ} \mathrm{C}$ attributed to the breakage of $\mathrm{C}-\mathrm{S}$. And the $\mathrm{C}-\mathrm{C}$ bonds linked to carboxyl carbon, carbonyl carbon, and aliphatic carbon possess the longer bond length in the range of 1.490 to $1.555 \AA$ and the lower bond order (0.993-1.044) are recognized as reaction sites. Meanwhile, the reactivity of $\mathrm{C}-\mathrm{O}$ bonds (in ether, hydroxy and carboxyl groups) is close to $\mathrm{C}-\mathrm{C}$ bonds, which may break at mild temperature. The aromatic rings have an effect on the bond strength, which makes $\mathrm{C}-\mathrm{N}$ exist in heterocycle and $\mathrm{C}-\mathrm{C}$ belonging to aromatic structures have much higher stability. The behavior of bondcleavage of molecular model is in accord with DTG analysis of HLH lignite.

\section{Conclusions}

In this present study, constructing lignite molecular model was to aid the comprehension of energy conversion process, such as pyrolysis, combustion, liquefaction, and gasification. The preliminary 2D molecular structure has been constructed according to the results of experimental methods. Elemental analysis is helpful for determining the formula $\left(\mathrm{C}_{200} \mathrm{H}_{195} \mathrm{~N}_{3} \mathrm{~S}_{1} \mathrm{O}_{32}\right)$, and thiophene, pyridine, pyrrole, benzene, naphthalene, phenol, and ether were selected as the representative structural units in the model base on ${ }^{13} \mathrm{C}$ NMR, FTIR, and XPS analysis. It is important to highlight the method of adjustment molecular model. Concentrations of main covalent bonds used to adjust molecular model can surmount the problem of selecting representative isomers as well as reflect the essence of chemical reaction. Nine main covalent bond concentrations of HLH lignite were calculated to examine and adjust the molecular model. And then, the optimized 3D conformation was obtained by MM and MD calculation in Materials Studio package (Accelrys). The total energy of optimized structure decreased sharply with excellent spatial structure. Finally, the sequence of bond-cleavage from DTG analysis and molecular simulations were used to examine the correctness of the $3 \mathrm{D}$ molecular model. A good agreement in the behavior of bond-cleavage during thermal reaction process between DTG analysis and molecular simulations. Although the constructed model is not the lowest energy conformation of HLH lignite, it is still valuable for considering the problem of isomers and essence of chemical reaction in constructing molecular model.

\section{Conflicts of interest}

There are no conflicts to declare. 


\section{Acknowledgements}

The authors gratefully acknowledge the financial support received from the National Natural Science Foundation of China (Grant No. 51676032) and Program for Changjiang Scholars and Innovative Research Team in University (No. IRT13052).

\section{References}

1 Z. P. Lei, M. X. Liu, H. F. Shui, Z. C. Wang and X. Y. Wei, Fuel Process. Technol., 2010, 91, 783-788.

2 Y. Xu, Y. F. Zhang, Y. Wang, G. J. Zhang and L. Chen, J. Anal. Appl. Pyrolysis, 2013, 104, 625-631.

3 Q. Q. He, K. Wan, A. Hoadley, H. Yeasmin and Z. Y Miao, Fuel, 2015, 156, 121-128.

4 P. Liu, D. X. Zhang, L. L. Wang, Y. Zhou, T. Y. Pan and X. L. Lu, Appl. Energy, 2016, 163, 254-262.

5 F. Castro-Marcano, M. F. Russuo Jr, A. C. T. van Duin and J. P. Mathews, J. Anal. Appl. Pyrolysis, 2014, 109, 79-89.

6 X. X. Li, M. Zhang, J. Liu and L. Guo, Mol. Simul., 2015, 41, 13-27.

7 J. P. Mathews, A. C. Van Duin and A. L. Chaffee, Fuel Process. Technol., 2011, 92, 718-728.

8 W. Fuchs and A. G. Sandhoff, Ind. Eng. Chem., 1942, 34, 567. 9 J. P. Mathews and A. L. Chaffee, Fuel, 2012, 96, 1-14.

10 I. Wender, Catal. Rev., 1976, 14, 97-129.

11 C. V. Philip, R. G. Anthony and Z. D. Cui, ACS Symp. Ser., 1984, 287-302.

12 E. A. Wolfrum, ACS Symp. Ser., 1983, 28, 15-17.

13 J. L. Faulon, P. G. Hatcher, G. A. Carlson and K. A. Wenzel, Fuel Process. Technol., 1993, 34, 277-293.

14 S. Bhoi, T. Banerjee, K. Mohanty, S. Bhoi, T. Banerjee and K. Mohanty, RSC Adv., 2015, 6, 2559-2570.

15 H. Kumagai, J. Hayashi, T. Chiba and K. Nakamura, Fuel and Energy Abstracts, 1999, 43, 2.

16 T. Takanohashi and H. Kawashima, Energy Fuels, 2002, 16, 379-387.

17 Ü. Lille, I. Heinmaa and T. Pehk, Fuel, 2003, 82, 799-804.

18 Z. Y. Liu, Sci. Sin.: Chim., 2014, 44, 1431-1438.

19 X. J. Guo, Z. Y. Liu, Q. Y. Liu and S. Lei, Fuel Process. Technol., 2015, 135, 133-149.

20 S. Lei, Q. Y. Liu, X. J. Guo, W. Z. Wu and Z. Y. Liu, Fuel Process. Technol., 2013, 108, 125-132.

21 B. Zhou, S. Lei, Q. Y. Liu and Z. Y. Liu, Fuel, 2016, 184, 799807.

22 A. Marzec, Fuel Process. Technol., 2002, 77, 25-32.

23 L. Qian, Y. J. Zhao, S. Z. Sun, H. W. Che, H. Chen and D. Wang, Fuel Process. Technol., 2014, 118, 327-334.

24 Q. Wang, Q. Liu, Z. C. Wang, H. P. Liu, J. R. Bai and J. B. Ye, Fuel Process. Technol., 2017, 160, 170-177.

25 S. R. Kelemen, M. Afeworki, M. L. Gorbaty, M. Sansone, P. J. Kwiatek, C. C. Walters, H. Freund and M. Siskin, Energy Fuels, 2007, 21, 1548-1561.
26 Z. K. Li, X. Y. Wei, H. L. Yan and Z. M. Zong, Fuel, 2015, 153, 176-182.

27 S. L. Mayo, B. D. Olafson and W. A. Goddard, J. Phys. Chem., 1990, 94, 8897-8909.

28 H. P. Gümüss, Ö. Tamer, D. Avc1 and Y. Atalay, Spectrochim. Acta, Part A, 2014, 129, 219-226.

29 M. J. Frisch, G. W. Trucks, H. B. Schlegel, G. E. Scuseria, M. A. Robb, J. R. Cheeseman, G. Scalmani, V. Barone, B. Mennucci, G. A. Petersson, H. Nakatsuji, M. Caricato, X. Li, H. P. Hratchian, A. F. Izmaylov, J. Bloino, G. Zheng, J. L. Sonnenberg, M. Hada, M. Ehara, K. Toyota, R. Fukuda, J. Hasegawa, M. Ishida, T. Nakajima, Y. Honda, O. Kitao, H. Nakai, T. Vreven Jr J. A. Montgomery, J. E. Peralta, F. Ogliaro, M. Bearpark, J. J. Heyd, E. Brothers, K. N. Kudin, V. N. Staroverov, R. Kobayashi, J. Normand, K. Raghavachari, A. Rendell, J. C. Burant, S. S. Iyengar, J. Tomasi, M. Cossi, N. Rega, J. M. Millam, M. Klene, J. E. Knox, J. B. Cross, V. Bakken, C. Adamo, J. Jaramillo, R. Gomperts, R. E. Stratmann, O. Yazyev, A. J. Austin, R. Cammi, C. Pomelli, J. W. Ochterski, R. L. Martin, K. Morokuma, V. G. Zakrzewski, G. A. Voth, P. Salvador, J. J. Dannenberg, S. Dapprich, A. D. Daniels, O. Farkas, J. B. Foresman, J. V. Ortiz, J. Cioslowski and D. J. Fox, Gaussian 09, Revision D. 01, Gaussian, Inc., Wallingford CT, 2010.

30 J. H. Xiang, F. G. Zeng, B. Li, Z. Li, L. M. Fen and L. H. Zhen, J. Fuel Chem. Technol., 2013, 41, 391-400.

31 X. H. Guan, Y. Liu, D. Wang, Q. Wang, M. S. Chi, S. Liu and C. G. Liu, Energy Fuels, 2015, 29, 4122-4136.

32 A. M. Gyul'maliev, G. S. Golovin and S. G. Gagarin, Solid Fuel Chem., 2007, 41, 257-266.

33 J. P. Wang, G. Y. Li, R. Guo, A. Q. Li and Y. H. Liang, Energy Fuels, 2017, 31, 124-132.

34 H. L. Lin, K. J. Li, X. W. Zhang and H. X. Wang, Energy Fuels, 2016, 30, 3809-3814.

35 F. Yang, Y. C. Hou, W. Z. Wu, M. Niua, S. H. Rena and Q. Wanga, Fuel, 2017, 189, 408-418.

36 J. H. Tong, X. M. Jiang, X. X. Han and X. Y. Wang, Fuel, 2016, 181, 330-339.

37 M. S. Solum, A. F. Sarofim, R. J. Pugmire, T. H. Fletcher and H. F. Zhang, Energy Fuels, 2001, 15, 961-971.

38 S. R. Kelemen, M. Afeworki and M. L. Gorbaty, Energy Fuels, 2002, 16, 1450-1462.

39 J. H. Xiang, F. G. Zeng, H. Z. Liang, B. L. Sun, L. Zhang, M. F. Li and J. B. Jia, J. Fuel Chem. Technol., 2011, 39, 481488.

40 K. M. Lu, W. J. Lee, W. H. Chen and T. C. Lin, Appl. Energy, 2013, 105, 57-65.

41 X. Ru, Z. Q. Cheng, L. H. Song, H. Y. Wang and J. F. Li, J. Mol. Struct., 2012, 1030, 10-18.

42 F. Weinhold, J. Comput. Chem., 2012, 33, 2363-2379.

43 K. Miura, K. Mae, M. Shimada and H. Minami, Energy Fuels, 2001, 15, 629-636. 